\title{
TRAUMATIC HEALING BAGI ANAK-ANAK KORBAN BENCANA GEMPA BUMI DI LOMBOK NUSA TENGGARA BARAT
}

\author{
Atri Dewi Azis ${ }^{1 *}$ dan Ansar ${ }^{2}$ \\ ${ }^{1}$ Program Studi Pendidikan Bahasa Inggris, Fakultas Keguruan dan Ilmu Pendidikan Universitas \\ Mataram \\ 2 Program Studi Teknik Pertanian, Fakultas Teknologi Pangan dan Agroindustri Universitas \\ Mataram \\ *) Korespondensi: atridewi75@unram.ac.id
}

Diterima 12 Juni 2019 / Disetujui 23 Juli 2019

\begin{abstract}
ABSTRAK
Setelah gempa bumi mengguncang Pulau Lombok pada tanggal 29 Juli 2018 dengan magnitude 6,4 SR masyarakat mengalami depresi dan trauma yang sangat dahsyat, sehingga membutuhkan traumatic healing yang diharapkan dapat menyembuhkan mental bagi korban bencana. Oleh karena itu, tujuan kegiatan ini adalah melakukan penanganan trauma (traumatic healing) bagi korban bencana khususnya anak-anak usia dini. Penanganan traumatic healing memiliki empat titik poin, yaitu fisik, emosional, intelektual, dan spiritual. Karena keempat titik poin tersebut merupakan prinsip keseimbangan dalam hidup manusia. Kegiatan yang lain adalah melakukan pembuatan teknologi hidroponik sebagai media untuk menanam sayur-sayuran di lokasi bencana. Metode yang digunakan untuk mencapai target tersebut adalah partisipatif. Metode ini berorientasi kepada upaya peran serta mitra secara langsung dalam berbagai proses kegiatan, mulai dari proses perencanaan, pelaksanaan sampai dengan evaluasi kegiatan. Jenis kegiatan yang telah dilakukan, antara lain sosialisasi kegiatan kepada anggota kelompok mitra, melakukan pendampingan dan traumatic healing kepada anak-anak korban bencana gempa bumi, melakukan permainan-permainan yang atraktif dan menyenangkan, outbond, dan pemberian hadiah kepada anak-anak, melakukan sosialisasi pembuatan teknologi hidroponik sebagai media untuk menanam sayur-sayuran di lokasi bencana.
\end{abstract}

Kata kunci: traumatic healing; gempa bumi; teknologi hidroponik

\section{PENDAHULUAN}

Masyarakat Lombok beraktivitas seperti biasa pada 29 Juli 2018 pagi. Semua berjalan relatif tenang, sampai akhirnya warga dikejutkan gempa yang mengguncang seisi pulau pada pukul 06.47 WITA. Semua orang panik karena tidak ada yang mengira akan terjadi gempa bumi berkekuatan 6,4 Skala Richter (SR) melanda bumi Seribu Masjid tersebut. Selang 7 hari, yaitu pada tanggal 5 dan 9 Agustus 2018 masyarakat kembali dibuat panik oleh gempa susulan berkekuatan 7,0 dan 6,2 SR. Badan Nasional 
Penanggulangan Bencana (BNPB) mencatat sebanyak 460 warga meninggal dunia, lebih dari 30.000 orang mengalami luka-luka, dan 71.962 rumah rata dengan tanah, sehingga warga harus mengungsi (Gambar 1).

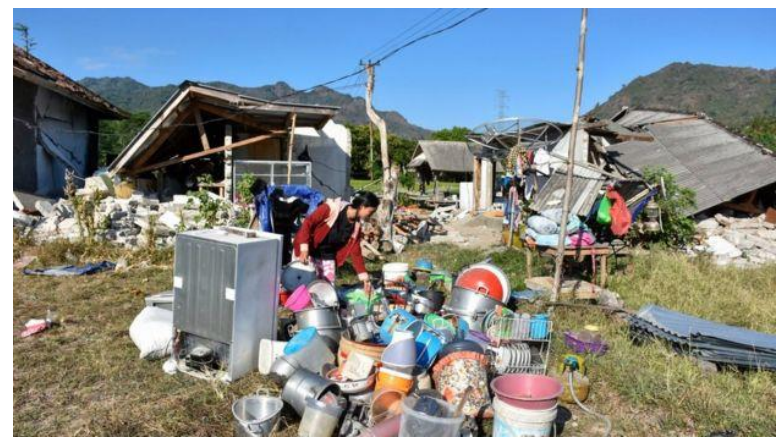

Gambar 1. Kondisi pemukiman warga pasca gempa bumi tgl 5 Agustus 2018 di Desa Kekait Kabupaten Lombok Barat.

Setelah gempa bumi mengguncang Pulau Lombok tersebut masyarakat mengalami kerugian material dan immaterial yang luar biasa. Bencana ini menimbulkan trauma yang sangat dahsyat, sehingga dibutuhkan traumatic healing yang diharapkan dapat menyembuhkan mental bagi korban agar dapat beraktivitas dan menjalani kehidupannya seperti sebelum bencana.

Fasilitas umum dan infrastruktur juga mengalami kerusakan yang cukup parah. Sebanyak 671 unit fasilitas pendidikan, 52 unit fasilitas kesehatan, 128 unit fasilitas peribadatan, 20 unit perkantoran, dan 6 unit jembatan mengalami kerusakan. Ketua BNPB, Sutopo menjelaskan bahwa kerugian ekonomi yang diakibatkan gempa Lombok dapat mencapai 7,45 triliun berdasarkan data yang dihimpun pada tanggal 13 Agustus 2018.

Pemulihan mental dan rehabilitasi infrastruktur pasca bencana memerlukan waktu yang lama untuk proses rehabilitasi dan rekonstruksi tersebut. Semua komponen bangsa ini harus bahu-membahu memberikan perhatian dan pemikiran guna melakukan pemulihan mental masyarakat yang mengalami musibah bencana. Salah satu yang dapat dlakukan adalah traumatic healing khususnya kepada anak-anak yang mengalami gangguan kejiwaan. Traumatic healing ini merupakan suatu tindakan untuk membantu orang lain mengurangi atau menghilangkan gangguan psikologis yang sedang mereka alami.

Berbagai model layanan traumatic healing telah dikonstruksikan untuk membantu para korban bencana, tetapi model yang sesuai sangat tergantung pada masalah dan kondisi lingkungan pendukungnya terutama seperti orangtua mereka. Pada prinsipnya traumatic healing yang diberikan kepada orang dewasa berbeda pada anak-anak. Pada anak-anak trauma healing dapat dilakukan melalui beberapa metode, misalnya teknik play therapy. Melalui teknik ini anak-anak diajak mengatasi traumanya melalui media permainan. Ada dua kelompok UKM yang dijadikan mitra pada kegiatan ini yaitu PAUD Lestari dan Kelompok ibu-ibu PKK yang berlokasi di Desa Kekait, Kecamatan Gunung Sari, Kabupaten Lombok Barat, NTB. Pemilihan lokasi ini didasarkan pada pertimbangan bahwa jumlah korban meninggal dunia sebanyak 15 orang, pemukiman penduduk $90 \%$ roboh, sarana peribadatan dan pendidikan juga rusak parah, sehingga tidak layak digunakan

Setelah bencana gempa bumi kelompok mitra pada umumnya masih menyimpan ingatan kejadian yang memilukan pada saat bencana datang menerpa. Secara psikologis korban bencana tidak mudah melepaskan ingatan yang terekam dengan kuat di memori otak. Bahkan terbawa hingga 
ke bawah alam sadar. Pada umumnya kelompok mitra PAUD Lestari dan Kelompok PKK 80\% masuk kategori trauma berat akibat kehilangan anggota keluarga, sehingga perlu penanganan khusus yang melibatkan para ahli psikologis untuk melakukan traumatic healing.

Permasalahan berikutnya adalah pemahaman kelompok mitra PAUD Lestari dan Kelompok ibu-ibu PKK tentang penanganan korban dan perlindungan anak dalam situasi bencana sangat terbatas. Selain itu, terbatasnya sumber daya bagi perlindungan korban, koordinasi, dan kerjasama oleh para pihak juga belum optimal.

Permasalahan yang lain adalah PAUD Lestari dan Kelompok ibu-ibu PKK telah kehilangan asset dan sumber daya yang dapat dijadikan sebagai sarana untuk mencari kebutuhan hidup. Pada umumnya kelompok mitra PAUD Lestari dan Kelompok ibu-ibu PKK telah kehilangan mata pencaharian seharihari yang sering mereka kerjakan, seperti pembuatan gula semut dari nira aren. Sarana dan prasarana yang mereka miliki telah hancur, bahkan ada yang telah tertimbun reruntuhan. Akibatnya kelompok mitra tidak dapat lagi memproduksi gula aren.

Kondisi psikis kelompok mitra yang masih labil dan mudah terprovokasi oleh isuisu yang beredar lewat media sosial. Misalnya pada jam sekian akan terjadi gempa susulan yang lebih besar dibanding gempa utama. Gempa susulan memang masih sering terjadi walaupun dengan skala yang lebih kecil dan durasi yang lebih singkat. Seharusnya lembaga yang memiliki otoritas seperti BMKG memberikan informasi yang akurat secara periodik agar tidak terjadi keresahan di tengah masyarakat. Dengan demikian, diperlukan penanganan korban bencana secara komprehensif agar mereka dapat beraktifitas kembali seperti biasanya.

\section{METODE KEGIATAN}

\section{A. Tempat dan Waktu}

Tempat pelaksanaan kegiatan yaitu di

Desa Kekait Kecamatan Gunung Sari Kabupaten Lombok Barat Propinsi Nusa Tenggara Barat. Jarak dari Mataram ke Desa Kekait $\pm 15 \mathrm{~km}$ yang berada di bagian utara Kabupaten Lombok Barat. Waktu pelaksanaan program ini yaitu dari bulan Maret-Agustus 2019.

\section{B. Khalayak Sasaran}

Sasaran pelaksanaan program kemitraan ini adalah Sekolah Pendidikan Anak Usia Dini (PAUD) dan ibu-ibu PKK yang berlokasi di daerah bencana gempa yaitu di Desa Kekait Lombok Barat.

\section{Metode Pendekatan}

Metode pendekatan yang digunakan dalam kegiatan ini adalah partisipatif, yaitu pendekatan yang berorientasi kepada upaya peran serta mitra secara langsung dalam berbagai proses dan tahap pelaksanaan kegiatan, mulai dari proses perencanaan, pelaksanaan sampai dengan evaluasi kegiatan. Kelompok mitra tidak hanya sebagai obyek kegiatan, tetapi juga sebagai pelaku kegiatan, sedangkan Tim Pelaksana hanya bertindak sebagai fasilitator dan motivator. Komitmen sinergi antara kedua belah pihak (kelompok mitra dan Tim Pelaksana) sangat penting untuk keberhasilan capaian target kegiatan.

Secara operasional seluruh kegiatan ini dijabarkan dengan beberapa tahapan sebagai berikut. 
1. Tahap Konfirmasi Rencana Kegiatan kepada Mitra

Konfirmasi rencana pelaksanaan kegiatan disampaikan kepada kelompok mitra sekaligus mendiskusikan tentang rencana tahapan kegiatan serta mencari persamaan persepsi tentang pentingnya kegiatan ini bagi mitra.

\section{Tahap Pelaksanaan Kegiatan}

Kegiatan pendampingan traumatic healing dilakukan dengan metode bercerita, dilanjutkan dengan metode permainan, outbond, dan pemberian hadiah bagi anak-anak. Model permainan disesuaikan dengan kondisi mental, jenis kelamin, dan umur anakanak. Kegiatan outbond dilakukan di tempat yang strategis dan menyenangkan bagi anak-anak yang didampingi oleh orang tua mereka. Melakukan sosialisasi teknologi hidroponik sebagai media untuk menanam sayur-sayuran di lokasi bencana.

3. Evaluasi Pelaksanaan Kegiatan

Evaluasi terhadap capaian target kegiatan dilakukan dengan menilai ketercapaian tujuan kegiatan pengabdian kepada masyarakat. Teknik evaluasi yang digunakan adalah pengamatan dan tanya-jawab langsung kepada kelompok mitra.

Kegiatan berlangsung selama 8 bulan. Beberapa jenis kegiatan yang telah dikerjakan, antara lain:

1. Sosialisasi kegiatan kepada anggota kelompok mitra.

2. Melakukan pendampingan dan traumatic healing kepada anak-anak korban bencana gempa bumi.

3. Melakukan permainan-permainan yang atraktif dan menyenangkan, outbond, dan pemberian hadiah bagi anak-anak.

4. Melakukan sosialisasi teknologi hidroponik sebagai media untuk menanam sayursayuran di lokasi bencana.

\section{HASIL DAN PEMBAHASAN}

\section{A. Observasi}

Observasi dilakukan beberapa tahap, yaitu dimulai dengan melakukan pendekatan kepada mitra mengenai kegiatan Program Kemitraan Masyarakat ini, khususnya kepada pengelola PAUD Lestari dan ibu-ibu PKK. Tahapan berikutnya adalah pemberitahuan kepada mitra terkait dengan kegiatan penyuluhan mengenai traumatic healing kepada anak-anak korban bencana.

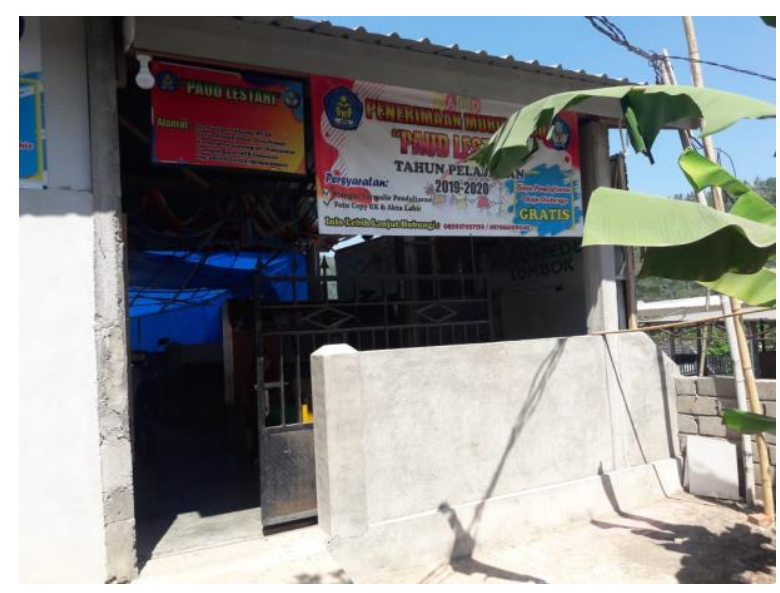

Gambar 2. Lokasi mitra PAUD Lestari

\section{B. Penyuluhan}

Proses observasi hingga penyuluhan telah berjalan selama 5 bulan secara intensif memberikan pendekatan dan pemahaman kepada mitra mengenai traumatic healing kepada anak-anak korban bencana. Penyuluhan dilaksanakan pada tanggal 27 Juli 2019 yang dihadiri 20 siswa PAUD termasuk kedua mitra. Partisipasi mitra 
sangat tinggi disebabkan kebermanfaatan kegiatan ini.

Selama ini mitra mengalami kerugian, baik material dan immaterial yang luar biasa. Bencana ini menimbulkan trauma yang sangat dahsyat, sehingga dibutuhkan penyuluhan traumatic healing yang diharapkan dapat menyembuhkan mental bagi korban agar dapat beraktivitas dan menjalani kehidupannya seperti sebelum bencana.

Fasilitas umum dan infrastruktur juga mengalami kerusakan yang cukup parah. Sebanyak 671 unit fasilitas pendidikan, 52 unit fasilitas kesehatan, 128 unit fasilitas peribadatan, 20 unit perkantoran, dan 6 unit jembatan mengalami kerusakan. Ketua BNPB, Sutopo menjelaskan bahwa kerugian ekonomi yang diakibatkan gempa Lombok dapat mencapai 7,45 Triliun berdasarkan data yang dihimpun pada tanggal 13 Agustus 2018.

Pada penuluhan ini juga disampaikan bahwa pemulihan mental dan fasilitas fisik pasca bencana memang memerlukan waktu yang lama untuk proses rehabilitasi dan rekonstruksi. Oleh karena itu, semua komponen bangsa ini harus bahu-membahu memberikan perhatian dan pemikiran guna melakukan pemulihan mental masyarakat yang mengalami musibah bencana. Salah satu yang dapat dlakukan adalah traumatic healing khususnya kepada anak-anak yang mengalami gangguan kejiwaan. Traumatic healing ini merupakan suatu tindakan untuk membantu orang lain mengurangi atau menghilangkan gangguan psikologis yang sedang mereka alami.

Bentuk partisipasi mitra cukup besar khususnya ibu-ibu PKK. Dukungan yang sangat besar dari masyarakat ini terlihat sangat antusias untuk mewujudkan PKM ini dan memberikan peluang besar pemulihan mental bagi anak-anak korban bencana. Pada kegiatan diskusi semua peserta begitu aktif dan sadar akan pentingnya pemulihan mental untuk menghadapi kehidupan yang lebih baik. Bencana dapat saja terjadi tanpa mengenal waktu dan tempat, sehingga manusia harus selalu tetap waspada untuk menghadapi takdir Yang Maha Kuasa ini dengan mempersiapkan diri dengan sebaikbaiknya jika terjadi bencana.

\section{Pelatihan dan Demonstrasi}

Pelatihan dilaksanakan setelah penyuluhan kepada mitra. Pelatihan dilaksanakan kemudian didemonstra-sikan oleh mitra dalam mengo-perasikan teknologi hidroponik.

Mitra beserta pelaksana pengabdian yang hadir sejumlah 15 orang. Pelatihan yang dilakukan mengenai cara pembuatan teknologi hidroponik sebagai media untuk menanam sayur-sayuran yang praktis. Selama ini mitra belum memanfaatkan pekarangan halaman rumah mereka untuk menanam sayur karena keterbatasan teknologi yang mereka miliki.

\section{Pendampingan}

Pendampingan merupakan ke-giatan yang menentukan keber-lanjutan dari program PKM ini. Kegiatan ini diharapkan memberikan jaminan kualitas bagi mitra untuk menjaga komitmen menggunakan teknologi hidroponik ini sebagai media tanaman sayur di sekitar halaman rumah mereka. Tahap pendampingan merupakan tahapan kontrol melalui pemantauan kondisi pemanfaatan teknologi hidroponik dalam menghasilkan sayur yang layak dikonsumsi. Apabila terjadi perubahan fungsi atau ada kerusakan pada alat tersebut, maka mitra 
dapat menginformasikan kepada Tim

Pelaksana kegiatan.

Pendampingan telah dilaksana-kan pada tanggal 11 Agustus 2019 dan 25 Agustus 2019 pasca pelatihan dan demonstrasi dilaksanakan. Pelaksana-an pendampingan dilakukan untuk melihat sejauh mana perkembangan dan tindak lanjut dari mitra setelah proses pelatihan dilaksanakan.

\section{KESIMPULAN DAN SARAN}

\section{A. Kesimpulan}

Berdasarkan hasil dan pembahasan, maka dapat disimpulkan sebagai berikut:

1. Kegiatan traumatic healing yang telah dilakukan dapat membantu mitra dalam mengurangi gangguan psikologis yang sedang mitra alami.

2. Metode traumatic healing yang telah diberikan kepada anak-anak PAUD Lestari menggunakan metode play therapy mampu memberikan keceriaan.

3. Hasil wawancara dengan kelompok ibuibu PKK diketahui bahwa mitra sangat senang dan akan terus menggunakan teknologi ini sebagai media tanam sayur-sayuran yang praktis.

\section{B. Saran}

Guna meningkatkan produk-tivitas usaha kelompok mitra, maka perlu dilakukan penambahan alat-alat penunjang sarana produksi seperti wadah penyimpanan sayursayuran setelah panen.

\section{UCAPAN TERIMA KASIH}

Tim kegiatan menyampaikan terima kasih kepada DRPM Dikti atas dukungan dana yang telah diberikan melalui skim PKM tahun Anggaran 2019, sehingga kegiatan ini dapat terlaksana dengan baik. Begitu pula kepada seluruh pihak-pihak yang telah membantu kegiatan pengabdian ini disampaikan terima kasih.

\section{DAFTAR PUSTAKA}

Ansar dan Nazaruddin, 2018. Pemanfaatan teknologi hidro-ponik sebagai media tanaman yang praktis. Jurnal Panrita Abdi, 2(2): 135-141.

Azis, AD., 2014. English for Youngers 2. FKIP Universitas Mataram.

Azis, AD., 2014. Daily English Conversation. FKIP Universitas Mataram.

Fahrawati, 2015. Growmore Pupuk anorganik $100 \%$ larut dalam air. http://www.Ipmsulsel.net/v2/index.p hp. Download: 29 Juni 2016.

Karsono, S., W. Sudarmodjo dan Y. Sutiyoso. 2002. Hidroponik Skala RumahTangga. Agromedia Pustaka. Jakarta.

Made, W., 2013. Lebih Satu Juta Wisatawan Kuliner. http:// bali.antaranews. com/lebih-sa-tu-juta-wisatawan-kelombok. Diakses: 23 Desember 2104.

Putradi, G., 2013. KLU Bidik 500 Ribu Wisatawan pada 2013.http:// info lombok.net/klu-bidik-500-ribuwisatawan-pada-2013/. Diakses: 14 Desem-ber 2014.

Wijaya, 2012. Pemkab Lombok Barat Optimalkan Potensi Lahan Pertanian. Primadona Lombok. 